\title{
Intensive Care and Beyond: \\ Improving the Transitional Experiences for Critically Ill Patients and their Families
}

\author{
Professor Wendy Chaboyer \\ Director \\ Research Centre for Clinical Practice Innovation \\ Griffith Health
}

\section{Professorial Lecture}

Thursday 19 May, 2005

GRIFFITH UNIVERSITY

Gold Coast Campus 


\section{Background}

Professor Wendy Chaboyer is a Registered Nurse (RN) who has been conducting research in critical care for over a decade. By focusing her research on patients, their families and the nurses who care for them, she has brought insight into the complex nature of the health services required by the critically ill. In 1982 Professor Chaboyer completed her initial RN training at a Canadian hospital. Later, she completed Bachelor and Master degrees in Canada and a PhD in Australia. Since immigrating to Australia in 1994, Professor Chaboyer has been active in the Australian College of Critical Care Nurses and is currently a national board member. In 2001 she played an instrumental role in the formation of the World Federation of Critical Care Nurses and to this day is a strong supporter of both these organisations. Throughout her academic career, Professor Chaboyer has been committed to improving the quality of clinical nursing research, has mentored a number of beginning nurse researchers and has sought to improve the care and outcomes of critically ill patients and their families.

"Without understanding a greal deal about how the chronically ill get through their days outside of health facilities, health personnel will never understand what they really need to know in order to give effecive care at the facilities_-and to ensure that the patients will not return more quickly than they should."

A. Strauss, Chronic Illness and Quality of Life, 1977 p. 6 


\section{Intensive Care and Beyond: Improving the Transitional Experiences for Critically Ill Patients and their Families}

\section{Introduction}

Critical illness or injury often occurs suddenly, without warning, and requires one to one care from specially trained nurses. In 2002, there were approximately 137,000 patients admitted to Intensive Care Units (ICUs) in 171 Australian hospitals. About 90\% of patients will live through their ICU experience, with more than $75 \%$ surviving to hospital discharge. Conservative estimates suggest an ICU bed costs more than $\$ 3,000$ per day, one reason that intensive care has also been termed 'expensive care'. However, because ICU beds only comprise about 2.5\% of all hospital beds, a lack of space for the critically ill is an everyday concern for many ICU managers. Thus, there is a need to ensure that once these specialist services are no longer required, timely transfer to the ward occurs. The focus of my research has been on the transitions ICU patients and their families face when they are discharged from ICU and on the provision of nursing services to ensure continuity of care during this time.

\section{Conceptual Underpinnings of the Research}

The term 'transition' is well known and has been described by anthropologists, psychologists and nurses. Early work by anthropologists on the 'rites of passage' suggested that this transition was a process of separation, change and incorporation. Since the 1980’s American nursing scholar Meleis has examined health transitions from a nursing perspective. She has defined it as "a passage or movement from one state, condition or place, to another”. This definition is simple, easy to understand, and congruent with every day use of the term. We have come to understand that health transitions are both complex and multidimensional and require individuals to incorporate new knowledge, alter their behaviour, and change their definition of 'self' in the social context.

ICU patients face a number of health transitions from the time they enter hospital to when they return home to convalesce. When patients are critically ill, both they and their families have a range of experiences that are generally foreign to them. As their condition stabilises, they often become more aware of their condition and surroundings, and their families are adjusting to foreign sights and sounds of the ICU. 
By the time patients are well enough to be transferred to the ward, they are developing an understanding of how sick they have been. Numerous studies have demonstrated that the constant presence of ICU nursing staff helps both patients and their families feel 'safe' during such an uncertain time. However, once patients are stable and begin to develop an appreciation of their condition and surroundings, they are transferred to the ward. And, when they are well enough, they are then discharged home; however, they rarely return home in the condition they left. Because these transitions occur relatively quickly, there is little time for patients to prepare for and adapt to them.

Continuity of care is a term that has been used to describe the provision of timely care across a number of health services, for example, from the ICU to the ward and from the ward to home. For nurses to ensure continuity of care occurs there must be an understanding of what has 'come before'. If there is no such understanding, there is the potential for 'dis-continuity of care' and patients and their families may miss out on crucial aspects of care they require. Not only is there a growing body of knowledge about ICU patients' experiences and transitions, there is also evidence that dis-continuity of care occurs. The body of work I present has focused on understanding patients and families experiences of their health transitions and on the provision of nursing services to promote continuity of care for these individuals.

\section{Following the Path of ICU Survivors ${ }^{1}$}

Historically, ICU nurses have wondered what happens to patients once they leave the unit but have lacked the involvement post ICU care required to gain an understanding of patient progress. However, recent interest in continuity of care has meant a much closer and rigorous examination of the illness trajectory for these critically ill patients and nursing staff have now begun to recognise that a stay in the ICU has long term implications for the patient and their family. Led by Michelle Foster and Joy Grace, nursing staff in the ICU at the Gold Coast Hospital began a quality activity that shed light on the long-term outcomes of their patients, and, as a visiting research fellow in the unit, I was invited to be part of this work. In a three year period (1998 - 2000), we undertook semi-structured telephone interviews with 222 long-term ICU patients who

\footnotetext{
${ }^{1}$ Chaboyer, W. \& Grace, J. (2003). Following the path of ICU survivors; A quality improvement activity. Nursing in Critical Care, 8(4), 149-155.
} 
had been in ICU for almost 13 days on average. During interviews, individuals were questioned about their physical condition such as mobility, activities of daily living, energy levels and sleep. In total, at least $40 \%$ of participants required assistance with some of their activates of daily living in the first year. Over half reported a weight loss and lack of energy with about a quarter stating they felt 'depressed'. Interestingly, whereas a third worked full-time prior to their ICU admission, less than $10 \%$ were working full-time a year later. Because of the nature of the sample and data collection, we recognised that the information gain from this quality activity could not be generalised to other groups. However, it did signal that these patients may face long-term problems and led us to a more formal study of the health status of ICU survivors.

\section{Health Status of ICU Survivors ${ }^{2}$}

The importance of health-related quality of life (HRQOL) as a relevant outcome measure for patients requiring ICU management has only recently been recognised. A better understanding of how this expensive service affects the health and well-being of its survivors will allow nurses and other health care professionals to plan for and provide appropriate follow-up care. A systematic review of the theoretical basis and instruments used to measure HRQOL was undertaken and findings from recent studies of the quality of life of ICU patients reviewed ${ }^{3}$. The review identified that ICU survivors generally have poorer HRQOL scores six to twelve month after ICU than during their pre-admission period. They also have lower HRQOL than the ageadjusted general population. Despite this apparent poorer state of health, participants often claimed to be satisfied with their HRQOL. However, no Australian studies were found which led us to undertake our first small HRQOL study.

Michelle Foster, Julia Creamer and I conducted a small pilot study of the health status of patients in 1999/2000 in order to gain a sense of the issues faced during recovery and to assess the feasibility of a larger, longitudinal study. This pilot was important because one major issue faced by researchers planning longitudinal research, or

\footnotetext{
${ }^{2}$ Chaboyer, W. , Foster, M. \& Creamer, J. (2002). Health status of ICU survivors: A pilot study. Australian Critical Care, 15(1), 21-26..

${ }^{3}$ Chaboyer, W. \& Elliott, D. (2000). Health-related quality of life of ICU survivors: A review of the literature. Intensive and Critical Care Nursing, 16(2), 88-97.
} 
studies that follow participants over time, relates to the fact that participants may 'lose interest' in the research and drop-out. Related to this, over time researchers may be unable to locate willing participants. An additional issue faced by those researching the ICU population is that some patients may be unable to participate in research due to their physical condition. In some instances, proxy respondents may be used however the researcher must always consider whether proxy responses will be accurate. In order to address these issues prior to a larger study, a pilot study was undertaken and recruited 20 patients and 20 next-of-kin 'proxies'. They were surveyed at four time points, during hospitalisation to gain a 'retrospective' understanding of their health status prior to hospital, and at one, six and twelve months to identify their current health status.

Figure 1 displays the results of the patient responses and identifies that initially, both the physical domains (functioning, role, pain and general health) and mental domains (vitality, emotions, social and mental health) were significantly decreased, however by one year, many report that their condition has improved, but generally not back to their pre-ICU status. Proxies were surveyed at one time point and their responses compared to patients. The research demonstrated that there was reasonably good correlation between next-of-kin proxies and patients for the physical domains, but the same was not true for the mental domains suggesting that proxy responses were not accurate and thus should not be used. At 12 months some participants declined to participate, others could not be found and some had died thus only 11 participants (55\%) completed the survey. When 'loss to follow-u' is greater than about $20 \%$ research findings may not be viewed as credible. Thus, for a number of reasons we did not pursue a larger study including the fact that a number of other large-scale studies on the health status of ICU survivors were published. However, one serendipitous finding was that family members asked if they could tell us about the toll this experience had on them, thus we began planning for a study of family carers. 
Figure 1: Health Status (SF-36) of ICU Survivors
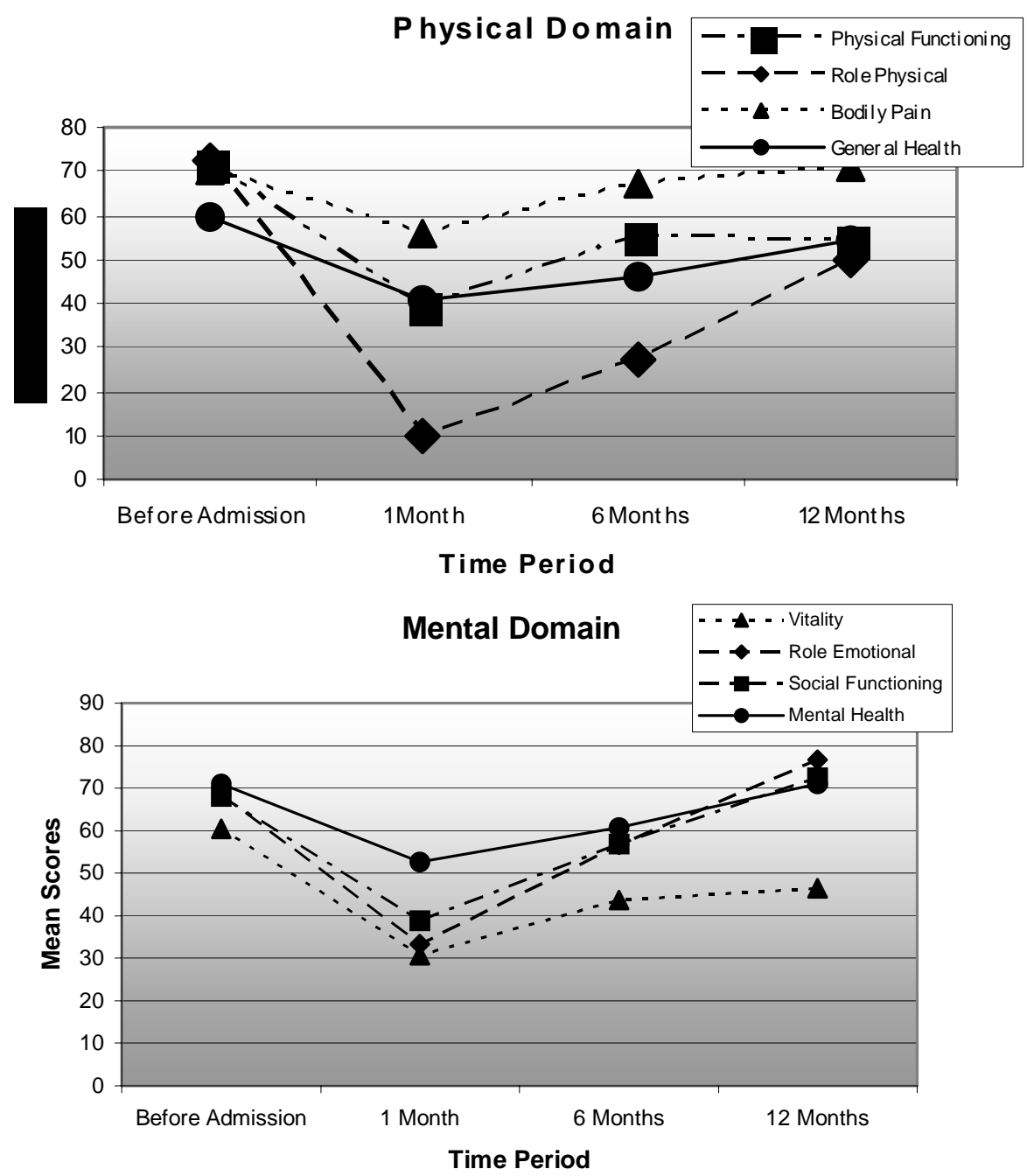

\section{Caregiver Burden ${ }^{4}$}

Family members often fulfill an informal caregiver role to ICU survivors who are still convalescing. However, these roles can be demanding and stressful, and because about 2/3 of ICU patients are male, the majority of carers will be female, who may have other 'caretaking' roles. Prior to conducting a formal study of caregiver burden, under the leadership of Trish Johnson, Michelle Foster, Roz van der Vooren and I undertook a synthesis of the literature, focusing on the ICU population ${ }^{5}$. This review identified that there were very few studies focusing on ICU patients, however one study revealed that only $15 \%$ of carers received community support and $75 \%$ of carers were hesitant to ask for assistance even when it was needed. A second study

\footnotetext{
${ }^{4}$ Foster, M. \& Chaboyer, W. (2003). Family carers of ICU survivors: A survey of the burden they experience. Scandinavian Journal of Caring Science, 17, 205-214.

${ }^{5}$ Johnson, P., Chaboyer, W., Foster, M. \& van der Vooren, R. (2001). Caregivers of ICU patients discharged home: What burden do they face? Intensive and Critical Care Nursing, 17, 219-227.
} 
demonstrated that there was an association between caregiver burden and both depression and financial strain.

Given this paucity of research, Michelle Foster and I planned a caregiver burden study. The aim of this study was to measure the burden associated with caring for a family member who had been critically ill. Seventy one family carers, 51 females (72\%) and 20 (28\%) males of long term intensive care patients completed a mailed survey three months after ICU discharge.

The amount of time caregivers spent caring was considerable, on average 36.9 hours per week. The vast majority $(n=59)$ did not use nursing services after discharge and about $60 \%(n=43)$ of the caregivers did not use family and friends to assist them in caring. Male carers received significantly more assistance than female carers (9.5 hours as compared to 1.6 hours). Carers reported a very low level of health service use including general practitioners, community nurses, paid nursing assistance and hospital services. These findings helped us understand that some families of ICU survivors are required to invest a significant proportion of their time to the carer role, and that they do not access health services in this role.

A related study Michelle Foster and I conducted examined the relationship between health status and caregiver burden in patient family dyads. At three months post-ICU we surveyed a group of 31 patients who required assistance and their family carers. This small study demonstrated a strong association between health status and carers' perceived burden in terms of the time it took, the physical care and their personal commitment. While we believe there is significant work to be done in this area, patients and families began telling us that many of these issues had their origins in the hospital, which led us to return our research to the hospital environment.

\section{Understanding the ICU Transfer Experience ${ }^{6}$}

Transfer out of the ICU has been identified as one of the most stressful aspects of the ICU experience for patients and families alike. If nurses are to assist patients and their

\footnotetext{
${ }^{6}$ Chaboyer, W., Kendall, E., Kendall, M. \& Foster, M. (in press). Transfer out of intensive care: An exploration of patient and family perceptions. Australian Critical Care (accepted 9 January, 2005).
} 
families with this transition, they must first have an understanding of the experience. Thus, in order to gain such an understanding of the ICU transfer experience, focus group meetings were held with ICU patients and their families. The four themes that emerged from the focus group discussions provided an important insight into the experiences of patients and their families as they made the transition from ICU to the ward, highlighting the complex and highly emotional nature of the experience. These themes included (1) a sense of sudden abandonment, (2) pervasive feelings of vulnerability and helplessness, (3) feelings of unimportance and (4) an ambivalence about the experience (or the presence of both positive and negative emotions). This understanding, and subsequent interviews focusing on the ICU transfer process conducted with ICU and ward nurses helped us develop a new, advanced practice nursing role, that of the ICU liaison nurse, whose role was to assist patients and families in their transitions to the ward and home and to promote continuity of care for this group.

\section{The ICU Liaison Nurse ${ }^{7}$}

The ICU liaison nurse role is an example of an advanced practice (AP) role in nursing. About 40 countries world-wide, including Australia acknowledge the AP role. The International Council of Nursing defines the AP Nurse/Nurse Practitioner as a "RN that has acquired an expert knowledge base, has complex decision making skills and clinical competence for extended practice" (www.inc-apnetwork.org). A Canadian group of researchers have demonstrated that important processes undertaken by the AP nurse include (1) provision of comprehensive care, (2) ensuring continuity of care, (3) coordination of care and (4) provision of timely services. They have also developed a model that can be used for evaluating AP nursing, termed the Nursing Role Effectiveness Model. This ‘structure process outcome' model has been used as a guide for our research.

As part of the development, implementation and evaluation a new AP nursing role at the Gold Coast Hospital, that of the ICU liaison nurse role, Michelle Foster and I undertook a qualitative study of the context and activities undertaken by all known

\footnotetext{
${ }^{7}$ Chaboyer, W., Foster, M. M., Kendall, E. \& Foster, M. (2004). The Intensive Care Unit Liaison Nurse: Towards a Clear Role Description. Intensive and Critical Care Nursing, 20, 77-86.
} 
Australian ICU liaison nurses. Previous literature suggests that outreach services in the UK may have developed for three reasons. First, patients were leaving ICU 'quicker and sicker' and as a result, required complex care during their ward stay. Second, ward nurses did not always have the knowledge, skills or time to provide such care, thus patients were at risk of deterioration and adverse events. Third, it was thought that the psychosocial trauma faced by these patients and their families on their transition to the ward might be lessened by support and contact with specialist nurses who have an understanding of the ICU experience. Whether this applied to the Australian context was unknown.

Using a naturalistic approach, semi-structured in-depth interviews were conducted with the six known Australian ICU Liaison Nurses and thematic analysis was undertaken. The findings are displayed in Table 1. The roles developed because of both service demands and the professional interest of the staff. Activities undertaken by these advance practice nurses included staff education and support, ward liaison, patient care and support and family education and support. While all liaison nurses described similar activities, the local hospital context dictated the extent to which they spent time on any one activity. Additionally, there was no pattern of service delivery with some sites offering Monday to Friday service 8 hours per day and others seven day service with 10-12 hours per day.

Table 1: Domains, Categories and Examples of the Liaison Nurse Role

\begin{tabular}{|c|c|c|}
\hline \multirow{3}{*}{$\begin{array}{l}\text { Domain } \\
\text { Historical } \\
\text { Development }\end{array}$} & Category & Examples \\
\hline & Service demands & $\begin{array}{ll}\text { - } & \text { ICU readmissions } \\
\text { - } & \text { Unplanned ICU admissions } \\
\text { - } & \text { Adverse events }\end{array}$ \\
\hline & Professional interest & $\begin{array}{l}\text { - } \text { Practice experience } \\
\text { - Knowledge } \\
\text { - } \quad \text { Previous research recommended the role }\end{array}$ \\
\hline \multirow[t]{4}{*}{ Activities } & $\begin{array}{l}\text { Staff education \& } \\
\text { support }\end{array}$ & $\begin{array}{l}\text { - } \quad \text { Formal in-services/short courses } \\
\text { - } \quad \text { Skill-training of ward staff } \\
\text { - } \quad \text { Addressing care management problems }\end{array}$ \\
\hline & Ward liaison & $\begin{array}{l}\text { - } \quad \text { Communication between ICU and ward } \\
\text { - } \quad \text { Preparing ICU \& ward staff for transfers } \\
\text { - } \quad \text { Assessing bed status, patient \& staff mix }\end{array}$ \\
\hline & Patient care \& support & $\begin{array}{l}\text { - } \quad \text { Monitoring patient status \& care } \\
\text { - } \quad \text { Case management } \\
\text { - } \quad \text { Emotional support }\end{array}$ \\
\hline & $\begin{array}{l}\text { Family education \& } \\
\text { support }\end{array}$ & $\begin{array}{l}\text { - } \text { Preparing families for ICU transfer } \\
\text { - Emotional support } \\
\text { - Practical assistance on ward }\end{array}$ \\
\hline
\end{tabular}


Interestingly, while most of the participants described collecting audit data, no formal research on the structures, processes and outcomes of the role had been undertaken. Thus, in planning for the implementation of the ICU liaison nurse at the Gold Coast Hospital, we adopted a strong focus on evaluation.

\section{Evaluation of the Role of the ICU Liaison Nurse}

\section{Impact on Patient and Family Anxiety}

The role of the ICU liaison nurse at the Gold Coast hospital was developed to focus on (1) providing psychosocial support of patients and their families, (2) improving discharge processes and (3) offering clinical support to ICU and ward nurses. A block intervention study was designed, with the first control and intervention periods followed by a wash-out and then a second period of control and intervention (sometimes denoted A, B, A, B). The hypothesis that the liaison nurse would decrease transfer anxiety experienced by both patients and families was tested as part of this study. The state component of the State-Trait Anxiety Inventory (STAI Form$\mathrm{Y}$ ) was used to measure anxiety quantitatively and focus group interviews were used to understand the transfer experience qualitatively, both before and after the implementation of the liaison nurse. Table 2 identifies that there was no measurable improvement in anxiety; however two trends became evident. The control group had scores similar to the norms for patients in general medical wards in hospitals and the intervention group had scores similar to the general population norms. Two factors may account for these findings including a small sample size, the timing of the actual data collection.

Table 2: Effect of the Liaison Nurse Intervention on Transfer Anxiety

\begin{tabular}{lcc}
\hline $\begin{array}{l}\text { Anxiety } \\
\text { (range 20-80) }\end{array}$ & $\begin{array}{c}\text { Control }(\mathrm{n}=35) \\
\text { Median (IQR) }\end{array}$ & $\begin{array}{c}\text { Intervention ( }=34) \\
\text { Median (IQR) }\end{array}$ \\
\hline Patients & $41(21)$ & $31(19)$ \\
Family & $42(28)$ & $39(17)$ \\
\hline
\end{tabular}

Interestingly, the findings from the qualitative component paint a different picture about the liaison nurse's effect. Table 3 contains the themes that arose from the 
analysis of this data and clearly demonstrate that transfer facilitated by the liaison nurse was associated with much more positive experiences.

Table 3: Transfer Experience Major Themes

\begin{tabular}{lll}
\hline \multicolumn{1}{c}{ Control } & \multicolumn{1}{c}{ Intervention } \\
\hline - Sudden abandonment & $\bullet$ Safe and confident \\
- Vulnerability & $\bullet$ Calm and settled \\
- Unimportant & $\bullet$ Relaxed and comfortable \\
- Ambivalent & $\bullet$ Uncertainty \\
\hline
\end{tabular}

\section{Impact on Health Service Delivery $^{8}$}

One major focus of the Liaison Nurse role was on improving the ICU transfer process. Due to the recognition that ICU beds are in short supply and that timely discharge will result in better bed management, ICU discharge delay was studied. Similar to an American study, ICU discharge delay was defined as the time between when a patient was deemed medically ready for discharge to the time when the patient physically left the unit. A total of 186 patients (101 control and 85 intervention) were included in the study. In total 22\% $(n=40)$ experienced a discharge delay of 4 hours or greater, $30 \%(n=30)$ of patients in the control group and $12 \%(n=10)$ in the intervention group, a statistically significant finding, even after controlling for a number of demographic and clinical factors. Stated another way, using odds ratios, the control group were 3.2 times more likely to experience a delayed discharge. Given the costs and shortages of ICU beds, and the shortage of ICU nurses, initiatives such as the liaison nurse may assist in improving health service delivery.

\section{$\underline{\text { Impact on ICU Nurses }}^{9,10}$}

The liaison nurse undertook a number of activities aimed to assist ICU nurses in their ability to prepare patients and families for transfer from ICU and discharge home. As

\footnotetext{
${ }^{8}$ Chaboyer, W., Thalib, L., Foster, M., Elliott, D., Endacott, R. \& Richards, B. (in press). The impact of an ICU Liaison Nurse on discharge delay in patients who have a prolonged ICU stay. Anaesthesia and Intensive Care (accepted 16 August, 2004).

${ }^{9}$ Chaboyer, W., Foster, M., Kendall, E. \& James, H. (2002). ICU Nurses’ Perceptions of Discharge Planning: A Preliminary Study. Intensive and Critical Care Nursing, 18, 90-95.

${ }^{10}$ Chaboyer, W., Foster, M., Kendall, E. \& James, H. (2004). The Impact of a Liaison Nurse on ICU Nurses’ Perceptions of Discharge Planning. Australian Critical Care, 17(1), 25-32.
} 
such, both prior to and after the implementation of the role, 58 ICU nurses completed a survey on their perceptions of discharge planning. Table 4 provides a sample of responses to the 21 items on the survey. Significant improvements were noted on most items. It appears that the liaison nurse was positively able to influence ICU nurses perceptions of their role in the ICU transfer and hospital discharge process.

Figure 2: ICU Nurses Perceptions of Discharge Planning

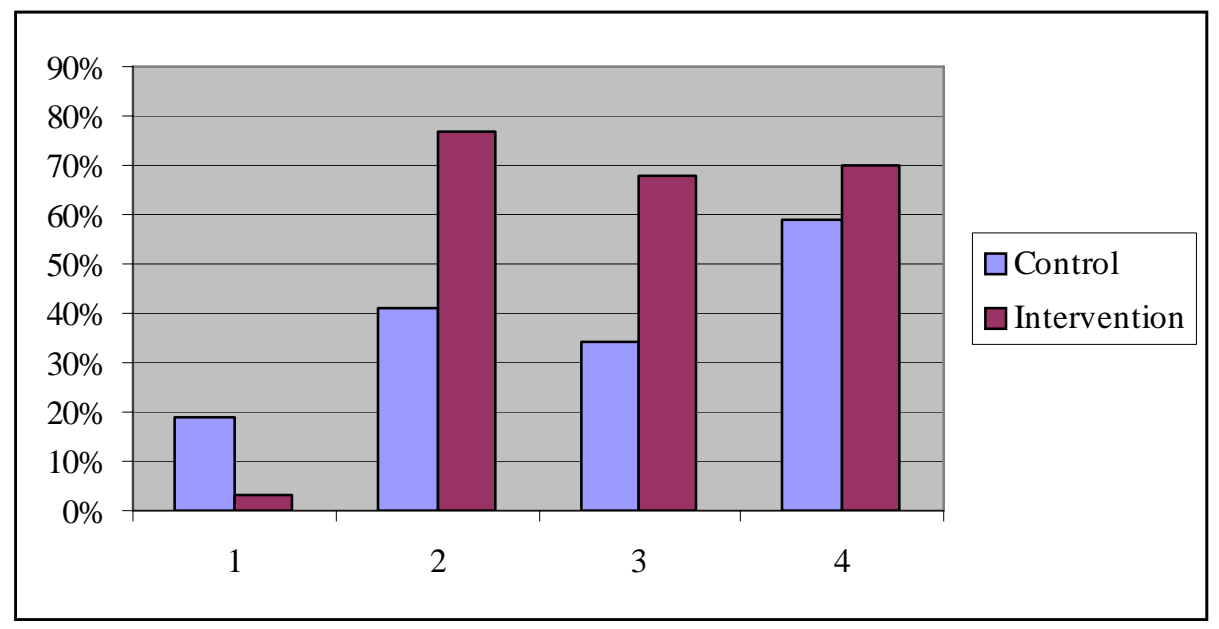

1: Discharge planning is premature in ICU

2: ICU staff have an understanding of discharge planning

3: Discharge planning is the responsibility of the bedside nurse

4: Discharge planning is time consuming

\section{$\underline{\text { Impact on Ward Nurses }}^{11}$}

While the liaison nurse role was designed to also support ward nurses, some authors have suggested that such roles have the potential to actually deskill ward staff and leave them feeling inadequate in their ability to care for patients. Thus, part of the evaluation of the ICU liaison nurse focused on ward nurses' perceptions of this new role. A total of 10 ward nurses who had experience with the ICU liaison nurse were interviewed individually. Two main themes emerged from the analysis and reflected the ward nurses' assessment of the role and its outcomes. Table 4 displays these findings and demonstrates that the role has been viewed positively by these ward nurses.

\footnotetext{
${ }^{11}$ Chaboyer, W. Gilespie, B., Foster M. \& Kendall, M. (in press). The Impact of an ICU Liaison Nurse: A Case Study of Ward Nurses Perceptions. Journal of Clinical Nursing (accepted 2 November, 2004).
} 
Table 4: Ward Nurses Perceptions of the Liaison Nurse Role

\begin{tabular}{ll}
\hline THEME & DESCRIPTORS \\
\hline Clinical Liaison & $\bullet$ Consultative expert \\
& - Change agent \\
& - Role model \\
& - Promoter of goodwill \\
& - Conduit between ICU and ward \\
& - Collaborator \\
& - Mediator \\
\hline Outcomes & - Augments patient transition to ward \\
& - Diffuses environmental shock \\
& - Higher standard of clinical competence \\
& - Smooth patient transition from ICU to ward \\
& - Increased preparation of family dynamics \\
\hline
\end{tabular}

In summary this evaluation demonstrated that the ICU liaison nurse has had a positive influence on critically ill patients and their families experience of ICU transfer, was beneficial for ICU and ward nurses and improved the ICU discharge process. Currently many Australian hospitals are adopting the role, despite the fact that no 'hard evidence' of the impact on patient outcomes is available, nor is the cost-benefit ratio of this service known. These facts have led us into two main areas of research. In the first, we are currently undertaking a study to determine which patients would most benefit from such a role and in the second we are proposing to conduct a multisite study of the effect of the ICU liaison nurse on adverse events and cost effectiveness. During my presentation I will briefly review what we have done to date on the first, and hope that in the future we will be able to report that we have completed the second.

\section{Intensive Care Nursing}

When I began this presentation, I mentioned that my research has focused on ICU patients, their families and the nurses who care for them. To this end I will conclude with a discussion of critical care nursing and briefly describe a couple of the studies that I have been involved with that have focused on the education of ICU nurses.

There are about 9,500 ICU nurses in Australia however not all work full-time. There are about 5,600 full time equivalent (FTE) ICU nurse positions in Australian ICUs 
(approximately 4,600 public and 1,000 private FTE positions). This means that there are about 3.7 FTE per open bed in the public sector and 2.0 FTE per open bed in the private sector. Approximately half of all nurses employed in ICUs have some form of critical care qualification, either a hospital certificate, or a university certificate, postgraduate diploma or degree.

The Australian College of Critical Care Nursing (ACCCN) is the professional organisation that represents critical care nurses nationally. This organisation is committed to improving critical care nursing practices, education and research. They have developed positions statements on staffing of critical care units and the education of critical care nurses. They offer a variety of continuing education opportunities and credential specialist critical care nurses. The ACCCN has developed a set of competency statements for critical care nursing practice that guide both hospitals in their provision of critical care services and universities in their preparation of clinicians. The ACCCN is one nursing organisation that offers a variety of research grants in order to further develop the body of critical care nursing knowledge. The ACCCN led the development of the World Federation of Critical Care Nurses $^{12}$, an organisation that represents critical care nurses at the international level and seeks to provide support for critical care nurses in less developed areas of the world. The Australian College and the World Federation have a fundamental interest in the education of critical care nurses and both recognise the importance of formal and informal education for critical care nurses.

In Australia in the early nineties postgraduate specialty education began moving from the hospital to the university sector, and in Queensland the first critical care course to be offered by a university was at Griffith University Gold Coast in 1993. This move to the tertiary sector saw a need for academics who specialise in critical care to have postgraduate degrees, and in 1994 I was recruited to coordinate a Master of Critical Care Nursing. Soon thereafter I became involved in two educational studies of critical care nursing. The first was jointly funded by the Confederation of Australian

\footnotetext{
${ }^{12}$ Williams, G., Chaboyer, W., Thornsteindottir, R., Fullbrook, P. \& Wojner, A. (2001). World wide overview of critical care nursing organisations and their activities. International Nursing Review, 48, 208-217.
} 
Critical Care Nurses (the ACCCN predecessor) and the Queensland Nurses' Union ${ }^{13}$, and the second involved an independent evaluation of the Griffith University critical care course $^{14}$. Both of these studies identified that critical care nurses wanted to obtain university standard education and university qualifications but they did not want to loose the focus on clinical practice that sometimes comes with 'academic' degrees. Because of these studies, and with the support of the then Dean of Nursing, Professor Anne McMurray and Director of the Nursing at the Gold Coast Hospital, Paul Kachel, the delivery of the critical care course adopted a collaborative model of delivery. Anne Evans Murray, the critical care educator at the Gold Coast Hospital became the first joint appointment in nursing and she and I worked together to deliver the critical care course, ensuring both university standards and clinical relevance. To this day, the critical care course is viewed to be academically rigorous while also maintaining quality clinical experience.

A few years later, I was part of a large national study ${ }^{15}$ that evaluated university critical care courses around the country. This multi-phase study examined course structure and content, clinical experience and student performance. Key stakeholders such as ICU staff, preceptors, managers and directors, students, facilitators were interviewed. Students knowledge was tested and their clinical performance assessed using direct observation. Interestingly, this study identified that length and content of courses and amount and type of clinical experience varied widely. However, there were no major differences in stakeholders' perceptions of the courses or the students. Additionally, there was no difference in the knowledge or clinical performance of the students despite the wide variation in the clinical experience provided by the courses. These findings support research in other areas of nursing where it has been demonstrated that it is not the duration or setting of education but more the quality of the experience during that education that impacts on nurses’ clinical abilities.

\footnotetext{
${ }^{13}$ Chaboyer, W., Theobald, K., Pocock, J. \& Friel, D. (1997). Critical care nurses' perceptions of their educational needs. Australian Journal of Advanced Nursing, 14(3), 15-20.

${ }^{14}$ Chaboyer, W. \& Retsas, A. (1996). Critical care graduate diploma nursing students needs identified in evaluation. Australian Critical Care, 9(1), 10-13.

${ }^{15}$ Chaboyer, W. P., Dunn, S., Aitkin, L., Theobald, K. \& Perrot, J. (2001). Critical care education: An examination of students’ perspectives. Nurse Education Today 21, 526-533.
} 


\section{Other Critical Care Research}

The table below acknowledges another group of critical care researchers (in alphabetical order) who I have had the privilege to work with as a co-researcher. By undertaking high quality clinical research, each of these researchers has contributed to improved care for critical care patients and their families.

\begin{tabular}{|l|l|}
\hline Chief Investigator & Research \\
\hline Julia Crilly & Violence in Emergency Departments \\
\hline Michelle Foster & Extended daily dialysis in the ICU \\
\hline Lynelle Foster & Haemodialysis catheter infections in ICU \\
\hline Elizabeth Gass & Physiotherapy practices in ICU \\
\hline Lise Gustad & ICU patients' transfer anxiety \\
\hline Denise Harris & Expanded practice in ICU Nursing \\
\hline Desley Horn & Enteral feeding in Paediatric ICU \\
\hline Tony Limpus & The use of graduated compressions stocking in ICU \\
\hline Michiyo Oka & Dietary behaviours of haemodialysis patients \\
\hline Brent Richards & Central venous catheter infection rates \\
\hline Brigit Roberts & Dreams and delirium experienced by ICU patients \\
\hline Mieko Sagawa & Adherence in haemodialysis patients \\
\hline Karen Wallen & Post-traumatic stress in ICU survivors \\
\hline Ged Williams & Worldwide organisation of critical care nurses \\
\hline
\end{tabular}

\section{Conclusions}

Understanding patients' and families' experiences can provide a foundation for improving nursing services. The ICU liaison nurse is one example of an advanced practice role that may improve patient outcomes, service delivery and staff skills. Numerous individual studies of a variety of ICU practices have been undertaken, but without a programmatic focus to research, clinical practice will be slow to respond to research findings. Importantly, collaborations between the university and hospital sectors results in clinically important research questions being pursued. The results of such research will likely improve patient care and outcomes and help develop the discipline of nursing. 


\section{ICU Related Publications}

Chaboyer, W. \& Creamer, J. (1999). Intellectual work of the critical care nurse: Applications from a qualitative study. Australian Critical Care, 12(2), 66-70.

Chaboyer, W., Dunn, S., Aitkin, L., Theobald, K. \& Perrot, J. (2001). Critical care education: An examination of students' perspectives. Nurse Education Today 21, 526-533.

Chaboyer, W., Dunn, S. V. \& Najman, J. (2000). Developing specialty knowledge: The case of Australian critical care nursing. Intensive and Critical Care Nursing, 16(1),13-17.

Chaboyer, W. \& Elliott, D. (2000). Health-related quality of life of ICU survivors: A review of the literature. Intensive and Critical Care Nursing, 16(2), 88-97.

Chaboyer, W. \& Forrester, K. (2000). The use of proxy-generated health status assessments in ICU survivors: The issue of quality of life. Journal of Law and Medicine, 8, 157-163.

Chaboyer, W., Forrester, K. \& Harris, D. (1999) The expanded role of acute care nurses: The issue of liability. Australian Health Review, 22(3), 110-117.

Chaboyer, W., Foster, M. \& Creamer, J. (2002). Health status of ICU survivors: A pilot study Australian Critical Care, 15(1), 21-26.

Chaboyer, W., Foster, M. M., Kendall, E. \& Foster, M. (2004). The Intensive Care Unit Liaison Nurse: Towards a Clear Role Description. Intensive and Critical Care Nursing, 20, 77-86.

Chaboyer, W., Foster, M., Kendall, E. \& James, H. (2004). The Impact of a Liaison Nurse on ICU Nurses' Perceptions of Discharge Planning. Australian Critical Care, 17(1), 25-32.

Chaboyer, W., Foster, M., Kendall, E. \& James, H. (2002). ICU Nurses’ Perceptions of Discharge Planning: A Preliminary Study. Intensive and Critical Care Nursing, 18, 90-95.

Chaboyer, W., Gass, E., Foster, M. (2004). Patterson of Chest Physiotherapy in Australian Intensive Care Units. Journal of Critical Care, 19, 145-151.

Chaboyer, W. Gilespie, B., Foster M. \& Kendall, M. (in press). The Impact of an ICU Liaison Nurse: A Case Study of Ward Nurses Perceptions. Journal of Clinical Nursing (accepted 2 November, 2004).

Chaboyer, W. \& Grace, J. (2003). Following the path of ICU survivors; A quality improvement activity. Nursing in Critical Care, 8(4), 149-155.

Chaboyer, W., James, H. \& Kendall, M. (in press). Transitional care after ICU: Current trends and future directions. Critical Care Nurse (accepted 30 November, 2003). 
Chaboyer, W., Kendall, E. \& Foster, M. (2002). Use of the Blaylock Risk Assessment Screening Score to Identify ICU Patients Who May Have Complex Hospital Discharge Planning Needs. Nursing in Critical Care, 7, 171-175.

Chaboyer, W., Kendall, E., Kendall, M. \& Foster, M. (in press). Transfer out of intensive care: An exploration of patient and family perceptions. Australian Critical Care (accepted 9 January, 2005).

Chaboyer, W., McMurray, A. \& Patterson, E. (1998). Unlicenced assistive personnel in the ICU: What is their role? International Journal of Nursing Practice, 4(4), 240246.

Chaboyer, W. \& Retsas, A. (1996). Critical care graduate diploma nursing students needs identified in evaluation. Australian Critical Care, 9(1), 10-13.

Chaboyer, W., Thalib, L., Foster, M., Elliott, D., Endacott, R. \& Richards, B. (in press). The impact of an ICU Liaison Nurse on discharge delay in patients who have a prolonged ICU stay. Anaesthesia and Intensive Care (accepted 16 August, 2004).

Chaboyer, W., Theobald, K., Pocock, J. \& Friel, D. (1997). Critical care nurses’ perceptions of their educational needs. Australian Journal of Advanced Nursing, 14(3), 15-20.

Crilly, J., Chaboyer, W. \& Creedy, D. (2004). Violence towards emergency department nurses by patients. Accident \& Emergency Nursing Journal, 12, 67-73.

Foster, M. \& Chaboyer, W. (2003). Family carers of ICU survivors: A survey of the burden they experience. Scandinavian Journal of Caring Science, 17, 205-214.

Harris, D. \& Chaboyer, W. (2002). The expanded role of the critical care nurse: A review of the current position. Australian Critical Care, 15(4), 133-137.

Horn, D. \& Chaboyer, W. (2003). Enteral Feeding; A RCT comparing intermittent and continuous feeding regimes in critically ill children. The American Journal of Critical Care, 12, 461-468.

Horn, D., Chaboyer, W. \& Schluter, P. (2004). Gastric Residual Volumes in critically ill pediatric patients: A comparison of feeding regimes. Australian Critical Care, 17(3), 98-103.

Johnson, P., Chaboyer, W., Foster, M. \& Vander Vooran, R. (2001). Caregivers of ICU patients discharged home: What burden do they face? Intensive and Critical Care Nursing, 17, 219-227.

Limpus, A. \& Chaboyer, W. (2003). The use of graduated compression stockings in Australian intensive care units: A national audit. Australian Critical Care, 16(2), 5358.

Limpus, A., Chaboyer, W., Purcell, C., Schluter, P., Gibbs, H., Beller, E. \& 
Heatherington, R., (2003). The Effect of Body Position and Graduated Compression Stocking Length on Femoral Venous Blood Flow Velocity. Phlebology, 18(4), 198202.

McMurray, A., Theobald, K. \& Chaboyer, W. (2003/4). Researching Continuity of Care: Can Quality of Life Outcomes be Linked to Nursing Care? Contemporary Nurse, 16, 51-61.

Oka, M. \& Chaboyer, W. (2001). The Influence of Self-Efficacy and other Factors on Dietary Behaviours in Japanese Haemodialysis Patients. International Journal of Nursing Practice, 7, 431-439.

Oka, M. \& Chaboyer, W. P. (1999). Dietary behaviors and sources of support in hemodialysis patients. Clinical Nursing Research, 8(4), 302-317.

Richards, B., Chaboyer, W. \& Bladen, T. \& Schluter, P. (2003). The effect of central venous catheter type on infections: A prospective randomised clinical trial. The Journal of Hospital Infection, 54, 10-17.

Roberts, B. \& Chaboyer, W. (2004). Patients’ dreams and unreal experiences following ICU admission. Nursing in Critical Care, 9(4), 173-180.

Roberts, B., Rickard, C., Rajbhandari, D., Turner, G., Clarke, J., Hill, D., Tauschke, C., Chaboyer, W. \& Parsons, R. (2005). Multi-centre study of delirium in ICU patients using a simple screening tool. Australian Critical Care, 18(1), 6-16.

Sagawa, M., Oka, M. \& Chaboyer, W. (2003). The utility of cognitive behavioural therapy on chronic haemodialysis patient's fluid intake: A preliminary examination. International Journal of Nursing Studies, 40, 367-373.

Sagawa, M., Oka, M., Chaboyer, W. Wakako, S. \& Yamaguchi, M. (2001). Cognitive behavioral therapy for fluid control in hemodialysis patients. Nephrology Nursing Journal, 28(1), 37-39.

Williams, G., Chaboyer, W., Thornsteindottir, R., Fullbrook, P. Wojner, A. (2001). World wide overview of critical care nursing organisations and their activities. International Nursing Review, 48, 208-217. 